\title{
O Testamento do Licenciado em Ensino Albino Duarte de Oliveira (1777)
}

\section{The Testament of the Bachelor's Degree in Education Albino Duarte de Oliveira $(1777)$}

\section{El Testamento del Licenciado en Enseñanza Albino Duarte de Oliveira} (1777)

No século XVIII, raros foram os Testamentos de moradores da cidade do Natal (Rio Grande do Norte) que declararam os títulos de livros como patrimônio pessoal, como por exemplo, o de Albino Duarte de Oliveira. $\bigcirc$ Licenciado em Ensino Albino Duarte de Oliveira era possuidor de uma biblioteca composta por livros que circulavam por meio de empréstimos entre religiosos e leigos que cultivam o hábito da leitura naquele distante século XVIII.

A transcrição do Testamento de Albino Duarte de Oliveira (com alguns trechos inteligíveis que não interferem na sua compreensão) é de inigualável relevância como material documental para as vindouras pesquisas de História da Educação, de História da Leitura e de História Social e Cultural. O texto original com os livros grifados (pelo historiador que fez a transcrição), integrantes da Divisão de Documentos Manuscritos do Arquivo do Instituto Histórico e Geográfico do Rio Grande do Norte, representa uma das suas vontades, transcrito pelas regras do Arquivo Nacional Brasileiro.

Registo de Testamento com que faleceu o Licenciado Albino Duarte de Oliveira morador nesta Cidade do Natal, 16 de junho de 1777

1 - Em nome da Santíssima Trindade, Padre, Filho e Espírito Santo,

2 - três pessoas distintas e um só Deus verdadeiro em quem creio

3 - piamente. Saibam quantos este instrumento virem como no

4 - ano do nascimento de Nosso Senhor Jesus Cristo de mil setecentos

5 - e setenta e sete aos dezesseis dias do mês de junho nesta cidade

6 - do Natal, capitania do Rio Grande do Norte eu Albino Duarte

7 - de Oliveira estando em meu perfeito juízo e entendimento que [ilegível] Senhor me deu quando de pé valente e com saúde; 
8 - temendo-me porém da morte e desejando por minha alma no caminho da 9 - salvação por não saber o que Nosso Senhor de mim quer

10 - fazer e quando será servido livrar-me para si, faço este testamento

11 - na forma seguinte = Primeiramente encomendo a minha alma

12 - a Santíssima Trindade que a criou e rogo ao Eterno Pai que pela

13 - morte e paixão de seu Unigênito Filho a queira receber como

14 - recebeu a deste Senhor quando esperava na árvore da vera cruz, e peço

15 - a Santíssima Virgem Maria Senhora Nossa, que como minha

16 - especial advogada, com os títulos da Conceição da Apresentação

17 - do Rosário, do Monte do Carmo, dos Prazeres, das Angústias, da Boa morte 18 - e da Cruz queira acompanhar minha alma, e a não deixar só quando

19 - deste mundo partir: e ao mesmo peço ao Anjo da minha

20 - guarda, a Santo Albino Santo do meu nome; a Senhora Santa

21 - Ana, São Joaquim, São José, São Francisco de Assis, Santo

22 - Antônio, São Francisco de Paula, São Judas Apóstolo, São Gonçalo

23 - do Amarante, e a Santa Gertrudes Magna Santos de minha

24 - especial devoção e ao Senhor Bom Jesus das Dores, e a todos os

25 - Santos da corte dos céus sejam meus intercessores, queiram

26 - [ilegível] defender [ilegível] a minha alma, e por ela

27 - interceder [ilegível] para que vá gozando

28 - a aventura para que foi criada por que como

29 - verdadeiro cristão [ilegível] fé católica

30 - [ilegível] Igreja Católica Romana [ilegível] minha alma

31 - Rogo ao Senhor Manuel do Rego Freire de [ilegível] e a Senhor

32 - sargento mor Manuel [ilegível] e o

33 - Senhor João [ilegível] Marques Ferreira pelo [ilegível] por me

34 - fazerem mercê [ilegível] testamenteiro, a [ilegível]

35 - vai [ilegível] ou façam seus [ilegível] por dinheiro [ilegível], ou lei extravagantes, ou [ilegível] outra qualquer via ou [ilegível] se dar como sua [ilegível] para que todos juntos ou cada um [ilegível] 
36 - para bem do meu corpo e alma [ilegível]

37 - testamenteiros, procurar e requerer todo o meu direito e se [ilegível] para o que

38 - instituo e nomeio meu bastantes procuradores, feitores, agentes arrecadadores e

39 - obradores, seladores e os condecoro em outro quaisquer cargos que pelas 40 - ordenadas leis vias, ou direitos proceder tenho para em suas [ilegível] transferir,

41 - e ceder para que aos meus bens possam dispor, vender os que necessários

42 - forem para meu enterro, e funeral, e fazer tudo o mais para pertencer

43 - a minha fazenda, corpo, e alma em qualquer juízo ou tribunal [ilegível]. Ordeno que a meu corpo seja sepultado na matriz desta

44 - cidade no corpo da igreja de frente do Santíssimo Sacramento

45 - envolto em hábito de São Francisco acompanhado do meu

46 - reverendo pároco com capa pluvial e os mais reverendos párocos [ilegível]

47 - com cera ou luzes costumadas [ilegível] e aos meus [ilegível]

48 - que ao meu enterramento me cantem um [ilegível]

49 - em [ilegível] na igreja pelo amor de Deus não querendo assim

50 - se lhes satisfaça o que com eles se ajustar. Peço aos irmãos de Nossa

51 - Senhora do Rosário que pelo amor de Deus com suas opas formadas

52 - com cruz educiara acompanhem o meu corpo mais a cruz se

53 - pague benção querendo por esse respeito se thes pague tudo.

54 - Declaro que sou irmão das Confrarias do Santíssimo Sacramento 55 - de Nossa Senhora da Apresentação das Santas Almas, e de Santa 56 - Luzia e Santa Quitéria e todas estas me devem acompanhar.

57 - Ordeno que pelo meu falecimento se façam doze sinais, além das

58 - três da obrigação três de cada vez interpoladamente os quais durarão

59 - o tempo que a obrigação que o muito Reverendo Pároco,

60 - sabe muito bem o costume da Sé pois não é dar-se quatro dobres

61 - e acabou-se o sinal. Deixo que se por minha alma se digam as missas

62 - que puder ser no dia que eu falecer e não, e não podendo neste 
63 - ser no seguinte. Peço ao meu Reverendo Pároco pelo amor de Deus

64 - me faça o ofício da sua obrigação paroquial presente meu 65 - corpo, e não podendo ser no dia seguinte o mais breve que 66 - puder ser para que tenha esse sufrágio logo, estando em lugar 67 - que me aproveite, como espero em Deus, os merecimentos de Cristo Senhor

68 - Nosso, [ilegível] da Virgem Maria Senhora Nossa e 69 - Mãe. E no caso que a minha fazenda dê terça para mais, informe 70 - as disposições seguintes [ilegível] me faça outro que será o da 71 - obrigação [ilegível] feito por de corpo presente.

72 - Declaro que [ilegível] referida sejam [ilegível] de doze vinténs e 73 - por esta [ilegível] me mande dizer mais cinte, e uma pelos

74 - [ilegível] que me sustentaram com [ilegível] espiritual de 75 - [ilegível] e duas na cidade da Paraíba uma a São Francisco 76 - na sua lgreja por filho seu outra a Nossa Senhora do Carmo

77 - na sua igreja também por filho seu e das dezoito uma ao senhor

78 - Bom Jesus das Dores na primeira sexta-feira seguinte

79 - ao seu falecimento na sua capela, outra ao Anjo de minha guarda,

80 - outra ao Santo do meu nome outra e todos os santos, e santas

81 - da corte do céu e as mais a Nossa Senhora com os títulos invocatórios

82 - declarados na primeira lauda deste, e as Santas já também na

83 - [ilegível] declaradas as quais todas exceto as duas da Paraíba [?]

84 - [ilegível] dezoito como aqui acima digo. Peço

85 - que [ilegível] mais cinco com esmola de deputaçao ao Santíssimo

86 - Sacramento desta matriz no seu [ilegível] pelo meu Reverendo Vigário

87 - [ilegível] de sua [ilegível]. Assim amis outra a Nossa

88 - Senhora das Neves na Matriz da Paraíba [ilegível] com a

89 - mesma esmola todas por minha alma assim esta com as mais já

90 - declaradas. Declaro que sou natural da cidade da Paraíba Freguesia

91 - de Nossa Senhora das Neves, e nela batizado, filho legitimo de João

92 - Duarte de Oliveira e Maurícia Cesar [ilegível], já defuntos. 
93 - Declaro que a minha fazenda foi adquirida, e para ela não tenho 94 - herdeiros ascendentes e nem descendentes; sim cinco irmãos legítimos, 95 - Manuel de Oliveira Duarte, que dizem morar no Panema desta 96 - capitania, Antônio de Oliveira da Cruz solteiro, Maria de Oliveira 97 - da Assunção viúva, Rita Maria de Oliveira solteira moradores 98 - todos na cidade da Paraíba, e José Duarte de Oliveira falecido nela 99 - aonde deixou filhos legítimos, e se estes são meus herdeiros 100 - da minha fazenda não tenho senão a terça. Declaro que sou solteiro e 101 - possui a fazenda seguinte. Uma morada de casas de taipa em que moro 102 - a [ilegível] do sitio Nau do Rifole com as casas de vivenda notado e a 103 - metade dos pesqueiros velhos cuja meação do sítio pega [ilegível] 104 - residente que par mim arrematou o capitão Antônio da Rocha 105 - [ilegível] do reverendo Vigário declaro que importei iguais tenho uma 106 - sociedade com o mestre Manuel [ilegível] da Ribeira com meu 107 - [ilegível] e uma rede da costa de que esta apossado

108 - o dito sitio [ilegível] de que está apossado o dito meu compadre 109 - este foi passar com [ele] [ilegível] está por conta,

110 - [ilegível] de todos três, para [ilegível] os gastos [ilegível] ou com [ilegível] para [ilegível] dia haver que [ilegível] sociedade.

111 - Declaro que assim foi pelo como [ilegível] no passado de [ilegível] no [?] [ilegível] em [ilegível] mil reis e ao depois mais duas patacas, [ilegível] para [ilegivel]

112 - vinte mil [ilegível] os sócios [ilegível] dizem [ilegível]

113 - as pescarias três malho, em se [ilegível] estão pagam eles [ilegível] não pais ainda não apostamos [ilegível] se lhes estão pagos de tudo de mim falta [ilegível] aponte [ilegível] o que me aparece.

114 - Declaro que possuo um oratório com sete imagens,

115 - o Senhor Crucificado em cravos, resplendor da [ilegível] de ouro com 116 - [ilegível] João de Barros Coelho, Nossa Senhora da

117 - Conceição com cordão de ouro, e coroa de prata e uma de [ilegível], 118 - e resplendor de ouro e outro do mesmo [ilegível] do sobredito Barros

119 - Santo Antônio [ilegível] com seu menino em resplendor de ouro e 
120 - santo com três e resplendor de prata e outro de ouro com [ilegível] 121 - menino do mesmo em casa do sobredito São José com [ilegível] de 122 - prata, flores de ouro e os resplendores [ilegível] e outro [ilegível] da sobredita Santa Ana

123 - com resplendor da sua Santíssima Filha, de consorcio seu [ilegível], e outro de couro

124 - em casa do sobredito, e São Joaquim com cajado, resplendor de

125 - prata e outro de couro em casa do dito Barros, o Menino Jesus

126 - além do mais tem um relicário engaitado em ouro, e uma

127 - volta de cordão do mesmo uma banca em que está o [ilegível]

128 - escravas crioulas, Francisco Manuel duas mesas, uma com gaitas e

129 - chaves outra pequena de amarelo nova, dois tachos de cobre,

130 - uma grande e outro pequeno, e uma bacia do mesmo grande

131 - um ferro de engomar com duas línguas, dois pratos finos um

132 - entre fino e quatro da fábrica, uma frasqueira de amarelo

133 - nova sem ferragem, trezes frascos um copo, e outro de cálice,

134 - cinco garrafas, três pequeninas, uma ordinária, uma branca,

135 - um pacacho de vidro um candeeiro uma candeia uma cama

136 - com seu colchão, e cinco lençóis, um de linho velho e quatro de

137 - Hamburgo quase novos três fronhas uma camisa de banho

138 - comprida, uma sopeira já rachada, uma fina pequena

139 - sem coberta, um almofariz com sua mão, uma caipa de

140 - amarelo nova com dobradiças somente. Declaro que possuo uma

141 - canastra, uma enxada um espeto um ferro de covas e uma

142 - foicinha que deixo ao meu Francisco, e ao meu Manuel uma mala

143 - uma machadinha, e um machado e uma foice que há de dar meu

144 - comprado João Cardoso, declaro que possuo louça grossa de mesa,

145 - cozinha, e cantareira a qual deixo aos ditos meus dois escravos

146 - em partes iguais, declaro que possuo uns livros seguintes

147 - um repanço antigo umas Eras portuguesas três espanhóis

148 - Los Reis Nuevos de Toledo, La invitación de Cristo e outro 
149 - velho histórico de Toledo está emprestado ao capitão Bernardo de 150 - Castro Freire do qual tenho em meu poder outro antepremonitório, 151 - História do futuro que tenho ao presente o Reverendo Vigário desta 152 - cidade um Mestre da Vida, $\bigcirc$ pecador convertido, dois profanos 153 - livro de divertimento de estudiosos, um Larragua que emprestei 154 - há muitos anos ao capitão Manuel Pinto de Castro quase novo a um 155 - da vida da venerável Madre Mariana da Purificação, 156 - emprestado a Antônio Gomes Freire oficial de entalhar, 157 - e outro livro já velho / / Declaro que possuo mais os bens seguintes // 158 - quatro pares da fivelas de prata dois de sapatos e dois de 159 - calções / / três ceroulas de linho usadas, oito camisas de Bertanha, 160 - duas velhas remendadas, quatro novas e duas 161 - de França usadas / / Duas [ilegível] um de [ilegível] velho, outro de 162 - [ilegível] novo / / Dois capotes um muito velho outro quase novo / / 163 - Dois chapéus que deixo aos meus dois escravos, e a cada um uma camisa

164 - nova, e umas ceroulas / / Um vestido de dois [ilegível] azul com 165 - veste de damasquilho amarelo e meias de seda tudo usado com 166 - duas gravatas e umas chopas de couro // Outro vestido de pano fino bem

167 - tinto de preto com catiara do mesmo, e veste de veludo sem costas

168 - nem mangas sem nestas erbocaes que ainda não vesti e se está 169 - acabando na casa do oficial que é o cabo de esquadra Pinto / / 170 - Três colheres de prata / / Declaro que possui um espadim de prata que 171 - Ihe não sei o preço, o que meti no cofre em nome de Manuel José de 172 - Vasconcelos em vinte e sete de abril de sessenta e dois por seis mil reis que

173 - tirou para mim os quais estou devendo com todos os juros / /

174 - Declaro que o dito espadim ficou em meu poder por concessão do 175 - tesoureiro que então era o qual troquei por outro de mais peso 176 - que é o que tenho em casa / / Declaro que possui um par de esporas 
177 - de prata que pesam cinquenta e seis oitavas, e mais outras colheres

178 - de prata que com o dito par de esporas meti no cofre em nome do

179 - Licenciado Francisco de Paula Moreira em quinze de fevereiro

180 - de setenta e dois por dezessete mil reis que terei o juro, e tudo estou

181 - devendo // Declaro que com estes penhores meti mais para

182 - poder tirar a dita quantia uma colher de prata usada e um

183 - par de cadeados de armação que tudo é de Teresa crioula que

184 - foi minha escrava a quem se entregará // Declaro que com os ditos penhores

185 - meti mais no cofre dois pentes de bico cobertos de ouro [ilegível] de esquadra

186 - Vicente Rodrigues que em minha mão estava de penhor por dois mil e 187 - oitenta preço de uma mortalha para o defunto seu pai que [ilegível]

188 - mandei dar por Agostinho Cardoso a guarde logo paguei e o dito cabo de

8 deu,

189 - esquadra de deve a dita quantia menos oito, ou doze vinténs, que já me

190 - outro e um [roveter] e uma volta de cordão pertencem ao Ajudante

191 - Alexandre de Melo Pinto que em meu poder se acham segurando as quantias

192 - seguintes sete mil e duzentos reis de que me carreguei, e já dei contas

193 - na Tesouraria da confraria das moças desta Matriz de que sou

194 - tesoureiro quando ele era dos ausentes de dois enterros que devia pagar

195 - e não pagou. Um do doutor Domingos da Cunha Linhares e outro

196 - da defunta Cosma de Oliveira dos Santos cada um três e seiscentos

197 - reis de tumba, cruz e guiam que os acompanharam [ilegível]

198 - me deu o dito ajudante além dos sete mil e duzentos reis dei the

199 - passei recibo para suas contas na Tesouraria Geral dos trezentos

200 - quatro mil reis de dinheiro de empréstimo era seis já pagou dois

201 - e juntamente me deve mais o mesmo ajudante dois mil quinhentos

202 - e oitenta reis que por ele paguei aos órfãos filhos do defunto

203 - Gregório José Dantas Correia, reposição [ilegível] dou o Ministro 
204 - [ilegível] por um [ilegível] duzentos que eu havia feito [ilegível] 205 - e favor dado [ilegível] por [ilegível] mas

206 - juiz de direito [ilegível] em seu primeiro [ilegível] e assim [ilegível] de que [ilegível]

207 - dito de inventário [ilegível] do [ilegível] a dita quantia que a não 208 - negue nem as referidas [ilegível] desta mesma [ilegível] 209 - que agora declaro [ilegível] esta deve-me mais o dito ajudante [ilegível] todos

210 - da mesma forma no inventário do falecido João Freire da [ilegível] 211 - novecentos e oitenta reis que tudo faz a quantia de quatro mil 212 - novecentos [ilegível] setecentos e cinquenta reis. Declaro que possuo por 213 - animais seguintes: um pouco de gado vacum a pé desta cidade 214 - entregue a [ilegível] da Costa Gomes, filho do meu companheiro João da

215 - Costa Santiago, [ilegível] sabe [ilegível] estado, e [ilegível], e também 216 - as tabuas que eu tenho dado em minha vida, que já não são minhas 217 - e do mesmo é [ilegível] acusado que fica fronteiro [ilegível] de seu pai,

218 - terra que ocupa suposto fosse comprada com meu nome, algumas

219 - bestas e umas cabeças de gado no sertão entregues ao capitão 220 - Miguel Ribeiro Dantas no sertão, umas cabeças de gado na [ilegível] 221 - entregues a Pedro Correa Barbosa, e eles deram também 222 - [ilegível], estado e gênero e uma besta, um potrinho na Carnaúba, 223 - junto ao Capaba entregue a Duarte Gomes. Declaro que 224 - possuo duas selas uma boa com freio e estribos de ferro ou 225 - velha com freio, estribos e esporas de ferro, duas cangalhas, uma 226 - com um torno de ferro em prestada segundo a minha lembrança 227 - a Sebastião Cardoso batalha e umas burvacas, um chapéu 228 - de sol de couro e três torneiras, uma pequenina do [ilegível] 229 - uma navalha e sua pedra que deixo ao meu Manuel. Uns poucos 230 - de tijolos de fazer parede de fora. Declaro que o quintal das casas 231 - tem uma mangueira e vinte e oito pés de Laranjeira da tinha, 
232 - doze de fruto, e as mais não quatro agueiros desfruto e dois 233 - pequenos já com [ilegível] Declaro que as dívidas que devo e se me devem

234 - hão de ir em um rol, ou assento fora deste testamento mais casado

235 - a ele por razão de porque nas que eu pagar e nas que me pagarem

236 - e sem falecer antes de fazer o dito assento se hão de ir todas

237 - no meu livro de razão e com esta e essa verdade podendo

238 - dar contas no tribunal divino. Declaro que a minha irmã

239 - Maria de Oliveira e a seus filhos por respeito dela tenho dado

240 - setenta mil reis e a minha irmã Rita Maria vinte

241 - mil reis cujas quantias declaro pelo menor segundo a minha

242 - lembrança e se for de dinheiro digo de direito conforme as leis

243 - que haverem acerca dos testamenteiros ao tempo que este se abrir

244 - que elas entrera com isso e fazer [ilegível] para [ilegível] com

245 - os outros em igual parte se façam, e no caso que este tempo eu possa

246 - dispor de todo [ilegível] de minha fazer deixo o meu irmão

247 - Antônio de Oliveira setenta mil reis do bem, e mão a minha

248 - irmã Rita Maria cinquenta mil reis do [ilegível] minha

249 - afilhada e sobrinha Isabel Barbosa filha de minha

250 - irmã Maria de Oliveira por minha universal herdeira

251 - de todos os meus bens depois de pagas as minhas dívidas

252 - alegadas deixo ao meu testamenteiro dez mil reis do monte

253 - como dívida por ser a fazenda pouca pelo seu trabalho

254 - além da sua vintena que esta um da lei, e aqueles da minha

255 - vontade, e seu poder dispor de todos os meus bens

256 - ordeno se faça nesta matriz mais um ofício pelas almas de meus

257 - pais, mais uma capela de missas pelas [ilegível]

258 - defuntos e duas missas a Nossa Senhora do Rosário para

259 - os amparar e defender na hora da morte os meus dois escravos

260 - Francisco e Manuel e se for falecida e herdeira universal

261 - deixo então aos meus três irmãos da Paraíba, esse legado, 
262 - e herança, ou ao que deles três vivos for, e sendo todos 263 - três morto será [inteira] para os meus sobrinhos filhos da dita 264 - minha afilhada, e se porem tiver somente a terça da minha 265 - fazenda dela disponho pela maneira seguinte a qual lançaram 266 - o oratório com as imagens $=$ Deixo a do 267 - Senhor Crucificado ao Senhor Bom Jesus das Dores com obrigações de memorador 268 - dizer o Procurador ou [ilegível] o receber uma missa por minha 269 - alma e o mesmo senhor em sua capela em sexta feira = 270 - O Menino Jesus ao Santíssimo Sacramento desta Matriz com 271 - obrigação de cinco missas no seu altar = Nossa Senhora 272 - da Conceição, e São José a Nossa Senhora da Apresentação com 273 -obrigação de outras cinco missas = A Senhora Santa Anna 274 - e São Joaquim a Senhora Santa Anna da vila de São José 275 - com obrigação de três missas = Santo Antônio a Nossa Senhora 276 - do Rosário desta cidade com obrigação de uma missa 277 - e todas por minha alma e todas as imagens com os seus 278 - adornos que tem a caixa do oratório deixo as almas santas 279 - desta cidade, e não querendo as confrarias, ou quem o domina 280 - receber estas dádivas com este encargo se diz ponham 281 - para missa por minha alma em hasta publica [ilegível] 282 - ajuste. Declaro que todas as missas e as mais disposições que 283 - deixe terão da minha terça se só esta tiver mais [ilegível] 284 - toda a fazenda sairá de cada [ilegível] exceto o que se fizer com o 285 - corpo sobre a terra, que [ilegível] tudo desmonte, ainda que tenho 286 - só a terça = Declaro que possuo um por de sapatos de corda 287 - [ilegível] outro tixinetes do mesmo= Declaro que possui um 288 - banco e sete cadeiras de pau cinco de encosto, duas rosas 289 - e outra rosa picada tudo velho, e um pilão bom = 290 - Declaro [ilegível] que estavam entregues do meu 291 - gado é minha Santa [ilegível] que para declararem a verdade do 
292 - que sabe dos meus bens se [ilegível] de fazer juramento com [ilegível] 293 - Declaro que possuo uma veste de [ilegível] ditas

294 - [ilegível] do mesmo [ilegível] outro de [ilegível] muito moda, dois

295 - lenços de Bertanha novos de fiança um outro par de meias, 296 - umas de fio, e um par de pano. Deixo a Nossa Senhora das 297 - Neves minha padroeira cinco mil reis em dinheiro ou feitos 298 - bons, e outros cinco a Nossa Senhora do Carmo da Paraíba em 299 - dinheiro ou feito bons = Deixo quinze Tostões para que no dia do seu 300 - falecimento [ilegível] quinze Marias pobres para merecerem quinze 301 - marias de joelhos se poder ser = Nossa Senhora do Rosário 302 - por minha alma e se forem direitos melhor, e se se não achar 303 - tantas Marias de outros nomes e se todas ou parte não quererem 304 - se digam dou missas digo se digam seis missas pelas almas 305 - do Purgatório, uma de trezentos reis, a nossa Senhora do 306 - Rosário por minha alma o que deixo pois em dinheiro do remanescente 307 - da minha troça quando a haja o que duvido = Declaro que todas as 308 - disposições que aqui tenho feito eram satisfeitas de todo 309 - o monte se dito do poder dispor e não podendo seja da terça 310 - até aonde chegar preferindo a todas assim deixo por 311 - minha alma em segundo lugar as almas do purgatório 312 - e em terceiro os dez mil reis da Paraíba em quarto as doações 313 - que faço das imagens [ilegível] Declaro que possuo uma 314 - ampulheta de relógio de $4^{\circ}$ de área. Declaro que na primeira lauda deste

315 - testamento se acham duas entrelinhas, na segunda uma palavra 316 - acrescentada, e na sétima lauda e outra entre linha tudo [ilegível] 317 - e feito por minha mão. Declaro que já fiz outro testamento 318 - que se não aprovou, e assim só quero que esta valha, e a parecendo 319 - outro será nulo e só valerá qualquer que tiver estas palavras 320 - lesu fili David miserere mei = Peço aos meus testamenteiros 321 - vendam os meus dois escravos antes do inventários por que 
322 - quero que eles sirvam de sua eleição digo ao senhor de sua 323 - eleição procurado por eles e também por que assim darão 324 - mais que na praça, e por quanto esta é a minha última vontade 325 - do modo que tinha adito torno a pedir aos ditos meus 326 - testamenteiros retro nomeados que pelo amor de Deus e por me fazerem 327 - mercê queiram acertar esta testamentaria com a 328 - limitada paga dos dez mil reis só muito por ser pouca fazenda 329 - além de sua vintena = Declaro que possuo duas jarras 330 - uns potes de guardar farinha que tudo deixo aos meus dois 331 - escravos sobredito em igual parte e [ilegível] 332 - dos testamenteiros quiserem aceitar rogo a meu vizinho o 333 - capitão Manuel Inácio Pereira do Lago [ilegível] esta 334 - dita testamentaria com a declarada paga e vintena, de suposto 335 - este meu testamento principiado a dezesseis deste mês de 336 - julho, e no ano já no princípio declarado com saúde não 337 - a pude acabar se não hoje vinte e sete do dito mês e ano 338 - de mil setecentos e setenta e sete nesta dita cidade do Natal 339 - Capitania do Rio Grande do Norte na qual me assino 340 - com o meu sinal costumado sendo presente por testemunhas 341 - que também assinaram o licenciado Francisco Paulo [ilegível] 342 - o capitão João Luís Pereira, o tenente Manuel do Rego 343 - Freire de Mendonça, o licenciado João Domingues, Antônio Carneiro 344 - de Albuquerque e o ajudante Antônio de Barros Passos. 345 - Antônio Gomes Freire / / Albino Duarte de Oliveira / / Saibam quantos 346 - este público instrumento de aprovação de testamento, e última vontade 347 - virem que no ano do nascimento de Nosso Senhor Jesus Cristo de mil sete centros

348 - e noventa e sete anos aos vinte e sete dias do mês de julho do dito 349 - ano desta cidade do Natal Capitania do Rio Grande do norte e em casa

350 - de morada do licenciado Albino Duarte de Oliveira [ilegível] 
351 - 363, [metade do fólio ilegível]

364 - Rego [ilegível], Manuel Mendonça, João Damasceno Xavier Carneiro, 365 - Antônio Carneiro de Albuquerque Gondim, o ajudante Antônio de Barros 366 - Passos, Antônio Soares Freire, pessoas que reconheço e do testado e 367 - este as testemunhas e todas de mim reconhecidas pelas mesmas de que $\mathrm{se}$

368 - tratam que todos assinaram com o dito testador e eu Sebastião Cardoso 369 - Batalha tabelião do público judicial e notas desta sobredita cidade 370 - do Natal capitania do Rio Grande do Norte e seu termo por Sua 371 - Majestade Fidelíssima que Deus Guarde que escrevi e assinei de meu sinal

372 - público, e raso costumado de que uso dia e era [? ] declarado em fé de 373 - verdade // Sebastião Cardoso Batalha //Albino Duarte de Oliveira $1 /$

374 - Francisco Paulo Moreira / / João Luís Pereira / / João Damasceno 375 - Xavier Carneiro / / Antônio de Barros Passos / / Antônio Carneiro

14376 - de Albuquerque Gondim / / Manuel do Rego Freire // Antônio Gomes 377 - Freire // Não aceito a testamentaria / / Manuel do Rego Freire // Não

378 - aceito a testamentaria / / João Luís Pereira / / Não aceito a testamentaria. 379 - Cidade do Natal vinte e nove de setembro de mil setecentos e noventa e três / /

380 - Manuel Inácio Pereira do Lago / / Não aceito a testamentaria. Vila 381 - de São José, dezoito de novembro do mil setecentos e noventa e três // Manuel

382 - Gomes da Silva / / Não aceito este testamento. Vila Flor vinte e seis de 383 - novembro de mil setecentos e noventa e três // João Barbosa Marques 384 - Ferreira / / Não se continha mais em o dito testamento sua aprovação e 385 - aceitação dos testamenteiros, que eu o Padre José Felix dos Santos, escrivão da

386 - vara nesta cidade do Natal, Freguesia de Nossa Senhora da Apresentação 
387 - do Rio Grande do Norte aqui [ilegível] bem e fielmente do próprio testamento que

388 - me foi apresentado por parte do Doutor Pantaleão da Costa de Araújo 389 - vigário da vara e juiz dos [ilegível] da cidade aos nove dias do mês de 390 - novembro de mil sete centos e noventa e três eu o Padre José Felix dos Santos

Padre Felix dos Santos

Escrivão da Vara que o Escrevi e Assinei

Prof. Dr. Thiago do Nascimento Torres de Paula Fundação de Apoio à Pesquisa do Rio Grande do Norte (FAPERN - Brasil) Grupo de Pesquisa Laboratório de Experimentação em História Social https: / / orcid.org/0000-0002-448 1-4327 Email: thiagotorres2003@yhaoo.com.br 